\title{
Urinary Neutrophil Gelatinase-Associated Lipocalin as Predictor for Development of Hepatorenal Syndrome in Patients with Hepatic Cirrhosis
}

\author{
Jihan A. Shawky ${ }^{1}$, Soha E Khorshed ${ }^{1}$, Hany A. Labib ${ }^{2}$ \\ ${ }^{1}$ Department of Tropical Medicine, Faculty of Medicine, Zagazig University, Egypt \\ ${ }^{1}$ Department of Clinical Pathology, Faculty of Medicine, Zagazig University, Egypt
}

Corresponding Author Jihan A. Shawky

Mobile:

$+201119500071$

E mail:

jihan.shawky2013@ya hoo.com

Key words: Neutrophil gelatinaseassociated lipocalin, Hepatorenal syndrome, Liver cirrhosis
Background and study aim: Liver cirrhosis has many complications, hepatorenal syndrome (HRS) is one of the most serious complications of it. Neutrophil gelatinase-associated lipocalin (NGAL) is a protein expressed by injured kidney tubular epithelia, urinary NGAL levels rise early in cases of acute kidney impairment before elevation of serum creatinine. The aim of this study is to evaluate NGAL as a biomarker for early detection of HRS in patients with hepatic cirrhosis.

Patients and Methods: Seventy five patients were studied and divided into two groups, group (I) 50 patients with liver cirrhosis without impairment of kidney functions and group (II) 25 patients with

\section{INTRODUCTION}

Acute kidney injury (AKI) is a common complication in patients admitted to hospital with advanced liver cirrhosis, it is observed in approximately $20 \%$ [1]. In cirrhosis, AKI include pre-renal azotemia, acute tubular necrosis (ATN), and hepatorenal syndrome (HRS) $[2,3]$. HRS is a dangerous complication, it is functional impairment of kidney function as a result of abnormal hemodynamics leading to splanchnic and systemic vasodilatation associated with renal vasoconstriction [4]. Serum creatinine has been the most commonly used marker of AKI, but it is non-specific marker of kidney dysfunction, as it may be normal or near normal in patients with advanced liver cirrhosis despite of diminished kidney function which may be due to muscle cachexy which they suffer from [5], so AKI can develop before change in serum creatinine, therefore investigations of a biomarker for early identification of patients at risk is very important for early diagnosis, because delay in cirrhosis and impaired kidney functions. Urinary NGAL level were measured by ELISA.

Results: The mean value of urinary NGAL level in patients with liver cirrhosis was $50 \pm 33 \mathrm{ng} / \mathrm{ml}$ while in patients with cirrhosis and HRS was 750 $\pm 250 \mathrm{ng} / \mathrm{ml}$ which showed highly statistically significant difference between both groups of patients.

Conclusion: Urinary NGAL increases significantly in patients with liver cirrhosis associated with impairment of kidney function than in those with stable cirrhosis and normal kidney function, so it can be used as a marker for prediction of development of HRS in cirrhotic patients.

diagnosis not only affect AKI treatment outcome, but it worsens portal pressure elevation in patients with HRS [6,7].

Neutrophil gelatinase-associated lipocalin (NGAL) is a protein expressed by injured tubular epithelia of the kidney $[8,9]$. Urinary NGAL (NGAL) rises early in AKI, prior to elevation of serum creatinine [8-11], urinary NGAL is not affected by volume status, diuretic use or pre-renal azotemia [12]. Chronic kidney disease (CKD) does not induce NGAL expression [12]. Urinary NGAL has been shown to be useful marker in number of clinical settings as predictor of development of AKI and mortality $[13,14]$, but the information on the role of urinary NGAL in cirrhosis and HRS is very few $[15,16]$.

On this background, the aim of this study was to investigate urinary NGAL as early predictor for development of HRS in patients with advanced liver cirrhosis. 


\section{PATIENTSAND METHODS}

Seventy five patients with liver cirrhosis; 50 patients (group I) with liver cirrhosis without kidney affection serum (creatinine $<1.5 \mathrm{mg} / \mathrm{dl}$ ) and 25 patients (group II) with liver cirrhosis and impaired kidney functions (serum creatinine $\geq 1.5 \mathrm{mg} / \mathrm{dl}$ ), this value was chosen as it has been selected in several conferences and publications as cut off for impairment of kidney function in cirrhosis, admitted to Tropical Medicine Department and Intensive Care Unit from January 2012 to June 2013, patients were divided into two groups.

\section{Exclusion criteria:}

1- Urinary tract infection.

2- Pre-renal azotemia.

3- Chronic parenchymal kidney disease or patients on chronic hemodialysis.

4- Obstructive uropathy.

5- Malignancy.

All patients were subjected to the following:

- Full history taking.

- Thorough clinical examination.

- Complete blood picture.

- Liver and kidney function tests.

- Urine analysis.

- Glomerular filtration rate (GFR)was calculated according to Cockcroft-Gault formula [17].

- Urine NGAL level by ELISA (BioPorto Diagnostics Hellerup, Denmark).

- 24-h urine amount was measured.10ml urine sample was stored at $-80^{\circ} \mathrm{C}$ until measuring urine NGAL.

\section{Definitions}

Cirrhosis: The diagnosis of cirrhosis was based on a combination of clinical, biochemical and ultrasonographic findings.

\section{Impairment of Kidney Function:}

Impairment of kidney function was diagnosed when serum creatinine concentration was greater than $1.5 \mathrm{mg} / \mathrm{dL}$. This value of serum creatinine was chosen because it has been selected in several consensus conferences as cut-off to define impairment of kidney function in cirrhosis; (1) prerenal azotemia due to volume depletion was considered when patients had a history of fluid losses in the preceding days (due to either bleeding, diuretic overdose, or other causes), together with compatible findings, absence of other causes of impairment of kidney function, and reversibility of kidney impairment as indicated by decrease of serum creatinine below $1.5 \mathrm{mg} / \mathrm{dL}$ after fluid resuscitation; (2) chronic kidney disease (CKD) was defined by evidence of structural kidney abnormalities, proteinuria, and/or abnormal urine analysis, with a glomerular filtration rate of less than 60 $\mathrm{mL} / \mathrm{min}$ per $1.73 \mathrm{~m}^{2}$; (3) $\mathbf{H R S}$ was defined using the current definition of the International Ascites Club. HRS is a functional renal failure due to renal vasoconstriction and low renal perfusion. Kidney histology is normal or shows lesions that do not justify the decrease in the glomerular filtration rate (GFR). It is characterized by impaired renal function and marked abnormalities in the arterial circulation and activity of endogenous vasoactive systems. The traditional concept is that HRS is due to deterioration in circulatory function secondary to an intense vasodilation in the splanchnic circulation (peripheral arterial vasodilation hypothesis). During the last decade, however, several features suggest a much more complex pathogens [24-27]; (4) ATN was diagnosed in patients who had at least three of the following: hypovolemic and/or septic shock or treatment with potentially nephrotoxic agents, urine sodium greater than $40 \mathrm{mEq} / \mathrm{L}$, urine osmolality lower than $400 \mathrm{mOsm} / \mathrm{kg}$, and fractional excretion of sodium greater than $2 \%$ without diuretics $[28,29]$.

\section{Statistical analysis:}

Analysis of data was performed with Statistical Package for Social Science computer program (SPSS Inc., version 16.0, Chicago, IL). Numerical data were expressed as mean \pm standard deviation and range. Qualitative data were expressed as frequency and percentage. Fisher's exact test was used to examine the relation between qualitative variables. For quantitative data (normally distributed) comparison between two groups was done using student $t$-test and Man Whitney for nonparametric $(\mathrm{P}<0.05$; significant $)$.

\section{RESULTS}

Seventy five patients were included in this study, they were divided into two groups:

Group (I): 50 patients with liver cirrhosis without kidney affection (Normal kidney function tests).

Group (II): 25 patients with liver cirrhosis and impaired kidney functions. 
Table (1): Patients characteristics at time of hospital admission

\begin{tabular}{|c|c|c|c|}
\hline & $\begin{array}{c}\text { Group I } \\
\mathbf{N}=\mathbf{5 0}\end{array}$ & $\begin{array}{c}\text { Group II } \\
\mathbf{N}=\mathbf{2 5}\end{array}$ & $\mathbf{P}$ \\
\hline Age & $40 \pm 5$ & $38 \pm 8$ & $0.5^{*}$ \\
\hline Sex (Male / Female) & $30 / 20$ & $15 / 10$ & $0.43^{\$}$ \\
\hline $\begin{array}{l}\text { Liver function tests : } \\
\text { S. bilirubin }(\mathrm{mg} / \mathrm{dl}) \\
\text { Direct Bil }(\mathrm{mg} / \mathrm{dl}) \\
\text { ALT }(\mathrm{U} / \mathrm{L}) \\
\text { AST }(\mathrm{U} / \mathrm{L}) \\
\text { S. Albumin }(\mathrm{g} / \mathrm{dl}) \\
\end{array}$ & $\begin{array}{l}3.2 \pm 2.1 \\
1.5 \pm 1 \\
57.3 \pm 8 \\
73.5 \pm 25 \\
3 \pm 0.6\end{array}$ & $\begin{array}{c}5.2 \pm 3.1 \\
3.1 \pm 1.2 \\
79.5 \pm 10 \\
102.5 \pm 71 \\
2.8 \pm 0.8 \\
\end{array}$ & $\begin{array}{c}0.04^{*} \\
0.05^{*} \\
0.13^{+} \\
0.03^{*} \\
0.001^{+} \\
\end{array}$ \\
\hline $\begin{array}{l}\text { Kidney function tests } \\
\text { S. creatinine }(\mathrm{mg} / \mathrm{dl}) \\
\text { BUN }(\mathrm{mg} / \mathrm{dl}) \\
\text { GFR }(\mathrm{mil} / \mathrm{min}) \\
\text { S. Na }(\mathrm{mEq} / \mathrm{L}) \\
\text { S. Ka }(\mathrm{mEq} / \mathrm{L}) \\
\text { Urine } \mathrm{Na}(\mathrm{mEq} / \mathrm{L}) \\
\text { GFR }(\mathrm{ml} / \mathrm{min})\end{array}$ & $\begin{array}{c}0.9 \pm 0.2 \\
20 \pm 10 \\
80 \pm 23 \\
137 \pm 5 \\
4.2 \pm 0.6 \\
45 \pm 30 \\
78 \pm 30\end{array}$ & $\begin{array}{c}2.1 \pm 0.9 \\
50 \pm 18 \\
30 \pm 15 \\
130 \pm 6 \\
4.3 \pm 0.7 \\
29 \pm 21 \\
31 \pm 10\end{array}$ & $\begin{array}{c}<0.001^{*} \\
<0.001^{*} \\
<0.001^{*} \\
<0.001^{+} \\
0.03^{+} \\
<0.001^{*} \\
<0.001^{*}\end{array}$ \\
\hline Child Pugh Turcot Score & $8.6+2.2$ & $12.1 \pm 1.8$ & $<0.001^{+}$ \\
\hline MELD-Na Score & $14+4$ & $31 \pm 6$ & $<0.0001^{+}$ \\
\hline
\end{tabular}

* Man Whitney ${ }^{+}$test student $t$ test ${ }^{\$}$ Fisher's exact test

The demographic characteristics of patients are shown in Table 1. Highly significant impairment of kidney function in group II and significant increase in child score and MELDNa score.

Table (2): Urinary NGAL levels in studied groups

\begin{tabular}{|l|c|c|c|}
\hline & $\begin{array}{c}\text { Group I } \\
\mathbf{N = 5 0}\end{array}$ & $\begin{array}{c}\text { Group II } \\
\mathbf{N = \mathbf { 2 5 }}\end{array}$ & P \\
\hline $\begin{array}{l}\text { Urinary NGAL } \\
\text { Mean } \pm \text { SD }\end{array}$ & $50 \pm 30$ & $750 \pm 250$ & $<0.0001^{*}$ \\
\hline
\end{tabular}

Highly significant increase in urinary NGAL in patients with impaired kidney function than those with normal kidney function (Table 2).

Table (3): correlation of different laboratory parameters with urinary NGAL levels:

\begin{tabular}{|c|cc|}
\hline & \multicolumn{2}{|c|}{ Urinary NGAL } \\
& r & p \\
\hline Serum creatinine & 0.335 & 0.001 \\
\hline Child-pugh-Turcot score & $\mathbf{0 . 3 8 6}$ & $\mathbf{0 . 0 0 1}$ \\
\hline MELD-Na score & $\mathbf{0 . 6 1 5}$ & $<0.001$ \\
\hline
\end{tabular}

Significant positive correlation between urinary NGAL levels and serum creatinine $(\mathrm{r}=0.335, \mathrm{p}=0.001)$, also there was positive correlation between urinary NGAL levels with Child score and MELD-Na score $(\mathrm{r}=0.386, \mathrm{p}=0.001, \mathrm{r}=0.615, \mathrm{p}<0.001$ respectively, Table 3$)$. 
Table (4): Sensitivity, specificity, positive predictive value, negative predictive value and accuracy of urinary NGAL in diagnosis of HRS

\begin{tabular}{|l|l|l|l|l|}
\hline Sensitivity & Specificity & Ppv & Npv & Accuracy \\
\hline $\mathbf{8 9} \%$ & $\mathbf{7 5} \%$ & $\mathbf{7 0} \%$ & $\mathbf{8 8} \%$ & $\mathbf{8 7} \%$ \\
\hline
\end{tabular}

$\mathrm{Ppv}=$ positive predictive value $\mathrm{Npv}=$ negative predictive value

At cut off $110 \mathrm{ng} / \mathrm{ml}$ uNGAL has $89 \%$ sensitivity, $75 \%$ specificity, $70 \%$ positive predictive value, $88 \%$ negative predictive value and $87 \%$ accuracy for diagnosis of HRS(Table 4, Figure $1)$.

\section{ROC curve for HRS}

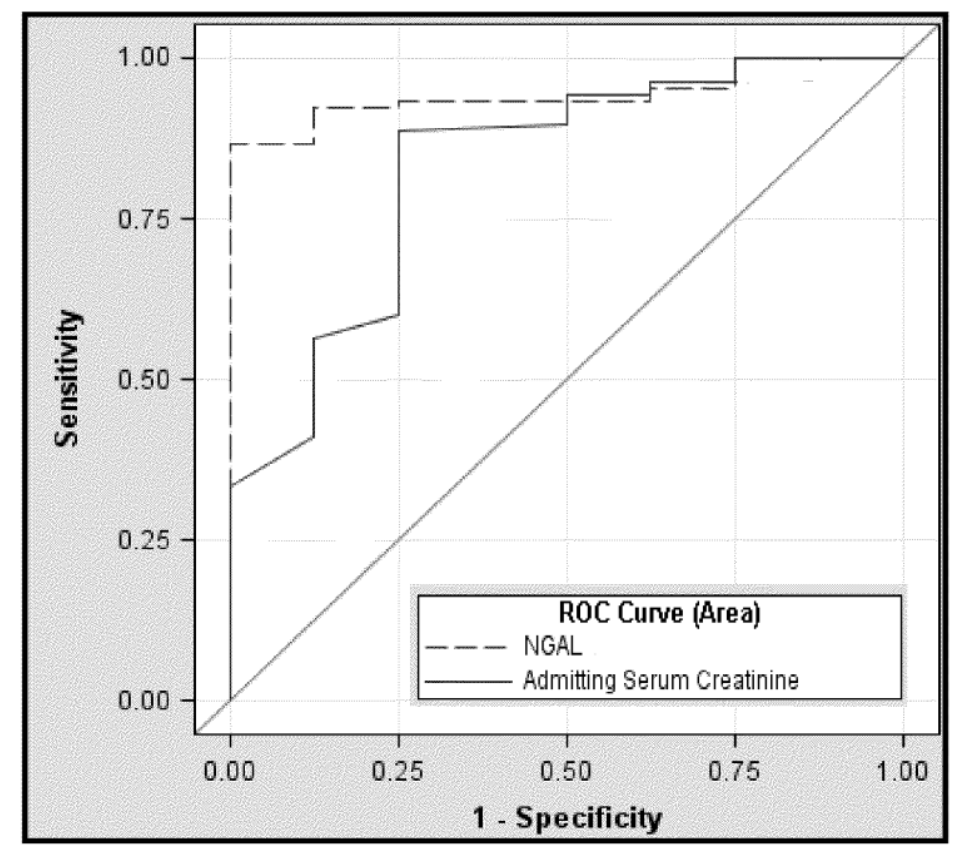

Figure 1: ROC curve for diagnosis of HRS using urinary NAGL

\section{DISCUSSION}

The result of this study showed that urinary NGAL was significantly higher in patients with liver cirrhosis and impaired kidney functions than in those without impaired kidney function, this result is in agreement with Gungor et al. [18] who found that patients with HRS had significantly higher plasma and urinary NGAL levels compared with stable cirrhosis patients and control subjects.

Also the result in agreement of Verna et al. [16] who evaluated the role of urinary NGAL in determining development of HRS and in patient mortality in patients with liver cirrhosis. Overall, 118 patients (44\%) of patients had normal kidney functions while the rest had impaired kidney functions. The result of that study showed that the elevation of urinary NGAL in HRS was intermediate between that of pre-renal azotemia and intrinsic AKI.

The result of current study is in agreement with Nickolas et al. [19] who found urinary NGAL in patients with AKI (416 mg/g creatinine) was significantly higher than in patients with pre-renal azotemia, chronic kidney disease or normal kidney function. But, the result of this study differ than that of Fagundes et al. [20] who found urinary NGAL levels are increased in patients with cirrhosis and ATN compared to those of several other causes as HRS this difference may be due to in the current study patients with impaired kidney functions were divided to HRS and ATN 
because no kidney biopsies were taken because of short life expectancy and potential bleeding complications due to coagulopathy.

The result of this study also is going with that of Singer et al. [21] who found urinary NGAL was significantly higher $(257 \mathrm{ug} / \mathrm{L})$ in patients with AKI compared to patients with pre-renal azotemia and unclassifiable causes (31 and 49 $\mathrm{ug} / \mathrm{L}$ respectively).

Singer et al. [21] found that a urinary NGAL cutoff level greater than $104 \mathrm{ug} / \mathrm{L}$ provided specificity of 0.88 for diagnosis of AKI with high positive likelihood ratio, whereas urinary NGAL cut-off level of $47 \mathrm{ug} / \mathrm{L}$ provided a sensitivity of 0.89 and a low negative likelihood ratio for exclusion of AKI.

In this study urinary NGAL sensitivity $89 \%$ and specificity $75 \%$,ppv70\%,npv $88 \%$ near that of Qasem[22] and El-Bassat [23] who-found(95.5\% ,90.2\%sensitivity,76.1\%,67.9\% specificity,65.5\% ,79\%ppv,and $99.2 \%, 91 \%$ npv respectively.

So, urinary NGAL can be used for early detection of kidney injury in patients with liver cirrhosis for rapid initiation of management and improvement of patient outcomes, which is our primary objective.

Ethical approval:Approved.

Funding:None.

\section{Conflict of interest:None.}

\section{REFERENCES}

1. Wong F, Nadim MK, Kellum JA et al. Working party proposal for a revised classification system of renal dys-function in patients with cirrhosis. Gut 2011; $60: 702-9$.

2. Martin-Llahi M, Guevara M, Torre A, Fagundes C, Restuccia T, Gilbert R et al. Prognostic importance of the cause of renal failure in patients with chrrhosis. Gastroenterology 2011; 140: 488-96.

3. Thabut D, Massard J, Gangloff A, Carbonell N, Francoz C, Nguyen-Khac E et al. Model for endstage liver disease score and systemic inflammatory response are major prognostic factors in patients with cirrhosis and acute functional renal failure. Hepatology 2007; 46:1872-82.

4. Wong F. Recent advances in our understanding of hepatorenal syndrome. Nat Rev Gastroenterol Hepatol 2012; 9: 382-91.
5. Schrier RW, Schekochikhin D, Gines P. Renal failure in cirrhosis : prerenal azotemia, hepatorenal syndrome and acute tubular necrosis. Nephrol Dial Transplant 2012; 27 : 2625-28.

6. Cereda JM, Roulot D, Braillon A, Moreau R, Koshy A, Lebrec D. Reduction of portal pressure by acute administration of furosemide in patients with alcoholic cirrhosis. H Hepatol 1989; 9 : 24651.

7. Garcia-Pagan JC, Salmeron JM, Feu F, Luca A, Gines P, Pizcueta P, et al. Effects of low sodium diet and spirono-lactone on portal pressure in patients with compensated cirrhosis. Hepatology 1994; 19:1095-99.

8. Mishra J, Ma Q, Prada A, Mitsnefes M, Zahedi K, Yang $\mathrm{J}$, et al. Identification of neutrophil gelatinase-associated lipocalin as a novel early urinary biomarker for ischemic renal injury. $J$ Am Soc Nephrol 2003; 14 : 2534-43.

9. Mishra J, Mori K,Ma Q, Kelly C, Barasch J, Devarajan P. Neutrophil gelatinase-associated lipocalin: a novel early urinary biomarker for cisplatin nephrotoxicity. Am J Nephrol 2004; 24 : 307-15.

10. Mishra J, Dent C, Tarabishi R, Mitsnefes MM, Ma Q, Kelly C, et al. Neutrophil gelatinaseassociated lipocalin (NGAL) as a biomarker for acute renal injury after cardiac surgery. Lancet 2005; 365: 1231-38.

11. Mori K, Nakao K. Neutrophil gelatinaseassociated lipocalin as the real-time indicator of active kidney damage. Kidney Int 2007; 71:96770.

12. Koyner JL, Vaidya VS, Bennett MR, Ma Q Worcester E, Akhter SA. Urinary biomarkers in the clinical prognosis and early detection of acute kidney injury. Clin J Am Soc Nephrol 2010; 5 : 2154-65.

13. Daniels LB, Barrett-Connor E, Clopton P. Plasma neutrophil gelatinase-associated lipocalin is independently associated with cardiovascular disease and mortality in community dwelling older adults : The Rancho Bernardo Study. J Am Coll Cardiol 2012; 59 : 1101-9.

14. Haase M, Bellomo R, Devarajan P, Schlattmann $\mathrm{P}$, Haase-Fieliz A. Accuracy of neutrophil gelatinaseassociated lipocalin (NGAL) in diagnosis and prognosis in acute kidney urinary : A systematic review and meta-analysis. Am J Kidney Dis 2009; 54 : 1012-24.

15. Gerbes AL, Benesic A, Vogeser M, Krag A, Bendtsen F, Møller S. Serum neutrophil gelatinase-associated lipocalin - a sensitive novel marker of renal impairment in liver cirrhosis ? Digestion 2011; 84 : 82-83. 
16. Verna EC, Brown RS, Farrand E, Pichardo EM, Forster CS, Sola-Del Valle DA, et al. Urinary neutrophil gelatinase-associated lipocalin predicts mortality and identifies acute kidney injury in cirrhosis. Dig Dis Sci 2012; 57 : 2362-70.

17. Cockcroft DW, Gault HM. Prediction of creatinine clearance from serumcreatinine. Nephron 1976; 16:31-41.

18. Gines A, Escorsell A, Gines P, Saló J, Jiménez $\mathrm{W}$, Inglada $\mathrm{L}$, et al. Incidence, predictive factors, and prognosis of the hepatorenal- syndrome in cirrhosis with ascites. Gastroenterology 1993;105:229-236.

19. Gines P, Rodes J. Clinical disorders of renal function in cirrhosis with ascites; in Arrovo V, Gines P, Rodes J, Schrier RW (eds): Ascites and Renal Dysfunction in Liver Disease: Pathogenesis, Diagnosis, and Treatment. Malden, Blackwell Science, 1999, pp 36-62.

20. Koppel MH, Coburn JW, Mims MM, Goldstei H, Boyle JD, Rubini ME. Transplantation of cadaveric kidneys from patients with hepatorenal syndrome: evidence for functional nature of renal failure in advanced liver disease. $N$ Engl J Med 1969;280:1367-1370.

21. Gines P, Guevara M, Arroyo V, Rodes J. Hepatorenal syndrome. Lancet 2003;362:18191827.

22. Schrier RW. Diagnostic value of urinary sodium, chloride, urea, and flow. J Am Soc Nephrol. 2011;22(9):1610-3.

23. Gill N, Natty JV Jr, Fatica RA. Renal failure secondary to acute tubular necrosis: epidemiology, diagnosis, and management. Chest, 2005;128(4):2847-63.
24. Gungor G, Ataseven H, Demir A, Solak Y, Gaipov A, Biyik M, Ozturk B, Polat L, Kiyici A, Ozlem O. Cakir and Polat H. Neutrophil gelatinase-associated lipocalin in prediction of mortality in patients with hepatorenal syndrome. Liver International 2014; 34 : 49-57.

25. Nickolas TL, O'Rourke MJ, Yang J, Sise ME, Canetta PA, Barasch N, et al. Sensitivity and specificity of a single emergency department measurement of urinary neutrophil gelatinaseassociated lipocalin for diagnosing acute kidney injury. Ann Intern Med 2008; 148-810-19.

26. Fagundes C, Pepin MN, Guevara M, Barreto R, Casals G, Sola E, et al. Urinary neutrophil gelatinase-associated lipocalin as biomarker in the differential diagnosis of impairment of kidney function in cirrhosis. J Hepatology 2012; 57 : 267-73.

27. Singer E, Elger A, Elitok S, Kettritz R, Nickolas TL, Barasch J, et al. Urinary neutrophil gelatinaseassociated lipocalin distinguishes pre-renal from intrinsic renal failure and predicts outcomes. Kidney Int 2011; 80 : 405-14.

28. Qasem AA, Farag SE, Hamed E, Emara M, Bihery A, Pasha H3.Urinary biomarkers of acute kidney injury in patients with liver cirrhosis. ISRN Nephrol. 2014, 6;2014:376795.

29. El-Bassat H, Ziada DH, Taha A, Alm-Eldin R. Urinary neutrophil gelatinase-associated lipocalin as a biomarker for the diagnosis of hepatorenal syndrome in cirrhotic patients. Tanta Med $J$ 2013;41:346-52.

Peer reviewer: Emad F Hamed, Assistant professor of Internal Medicine and Hepatogastroenterology, Faculty of Medicine, Zagazig University, Egypt. Mohamed H Emara, Lecturer of Tropical Medicine and Hepatogastroenterology, Faculty of Medicine, Zagazig University, Egypt.

Editor: Ibrahim Mohamed, Lecturer of Tropical Medicine and Hepatogastroenterology, Faculty of Medicine, Zagazig University, Egypt. 